\title{
MODERATING EFFECT OF TECHNOLOGY READINESS ON ADOPTION OF GEOTAGGING TECHNOLOGY AMONG SOCIAL NETWORKING SITES (SNSS) USERS FOR SMART TOURISM
}

\author{
Mohammad Badruzzaman BHUIYAN \\ Universiti Malaysia Perlis, Faculty of Applied Sciences and Humanities, Post-Doctoral Scholar, Malaysia, e-mail: bhuiyan.aisdu@yahoo.com
}

Md. Aminul ISLAM

Universiti Malaysia Perlis, Faculty of Applied Sciences and Humanities, Malaysia, e-mail: amin@unimap.edu.my.

Md. Ziaul HAQUE

Noakhali Science and Technology University, Department of Management Information systems, Noakhali, Bangladesh, e-mail: zia10093@yahoo.com

Chhanda BISWAS*

Universiti Utara Malaysia, College of Law, Government and International Studies,

School of Tourism, Hospitality and Environmental Management, 06010, Kedah, Malaysia, e-mail: chhandabiswasuum@gmail.com

\begin{abstract}
Citation: Bhuiyan, M.B., Islam, M.A., Haque, M.Z., \& Biswas, C. (2020). MODERATING EFFECT OF TECHNOLOGY READINESS ON ADOPTION OF GEOTAGGING TECHNOLOGY AMONG SOCIAL NETWORKING SITES (SNSS) USERS FOR SMART TOURISM. GeoJournal of Tourism and Geosites, 34(1), 47-55. https://doi.org/10.30892/gtg.34107-618
\end{abstract}

\begin{abstract}
More recently social networking sites (SNSs) users are extensively using the emerging geotagging technology for tourism motivation. The study aims to examine the relationship between determinants of geotagging technology and intention to adopt geotag technology as well as the extent to which technology readiness moderates the link between determinants of geotagging technology and intention to adopt geotag technology. Data were collected from a sample of 356 university students by using convenience sampling technique. Partial least square structural equation modelling has been used to measure the results. The empirical outcome uncovers that social influence, performance expectancy and facilitating condition are the factor that have direct impact on SNSs user's willingness to adopt geotag for smart tourism experience. The present paper enriches UTAUT model by understanding the association between two variables namely effort expectancy and performance expectancy as well as the moderating role of the technology readiness. The findings of the study will assist to SNSs service providers by understanding the moderating role of technology readiness in the relationship between determinants of geotagging technology and intention to adopt geotag technology.
\end{abstract}

Key words: Geotagging technology, SNSs, UTAUT, technology readiness, tourism

$* * * * *$

\section{INTRODUCTION}

Though the information exchange was unidirectional in traditional internet systems, the flow of information is bidirectional in recent years (Öz, 2015). By the advent of Web 2.0 technology, social media has exploded as a modern, innovative and creative aspect of human life. Recently, the amount of people who are unceasingly using the internet has touched to 4.39 (57\% of total population) billion in the world. 3.48 billion people are using social media actively that represent $79 \%$ of total internet users in the world. Around $94 \%$ active social media users use mobile phone to access different social networking sites (SNSs) that accounts for 3.26 billion people in the world (World Digital Report, 2019). Predominantly, the developing countries are experiencing significant usage of social media. The figure is 310 million for India, 34 million for Bangladesh, 47 million for Iran, and 6.2 million for Sri Lanka (World Digital Survey Report, 2019). This clearly means that in the developing countries such as Bangladesh, there are mere possibilities to exploit and implement the geotagging service among social network users (SNSs). In addition, social media providers offer a range of options attributable to a number of social media services such as text messenger, location-based services (LBS), social media games and social media payments. The four categories for these services are connectivity, information, entertainment and transactions. Location providers can also obtain a user site and push the related resources and information to the user depending on the customer's position across different social media services (Zhou, 2017). It will lead to better customer experience and encourage the plan to conduct (Zhou, 2013). LBS means "any operation that recognizes an entity's geography" (Junglas and Watson, 2008). A survey from Pew revealed that nearly $74 \%$ of matured mobile owners have ever utilized LBS for information such as getting road directions, using maps, and other related data (Pew Research Center, 2019).

Users of the technologies like social networking sites, location-based tracking and GPS (global positioning system) are commonly used to add or identify geolocation data with images and tags (Luo et al., 2011). More common tagging sites for location information for any user are Facebook, Instagram which are associated with their social network understanding of location (Haffner et al., 2018). Facebook, as well as a venue for improving tourist experience by presentation and self-identity, has been recognized as the biggest and fastest site for posting and sharing pictures (McLaughlin and Vitak, 2012; Rainie et al., 2012). Moreover, location becomes a commodity of its own in geo-surveillance (Rzeszewski and Luczys, 2018). In addition, there are currently no experiments in nature to examine the moderating impact of traveler technology readiness to use technology on their geographical experience. The aim of this paper is to examine the moderating impact of technology readiness and to store the research gap by using the well-known UTAUT model for embracing new technology. In this way, the research pursued two goals: to study the moderating impact of technology readiness on different connections between various constructs of a well-known theoretical model, namely UTUAT, and to define the effect of different UTUAT factors on the application of geotagging technologies among users of social networking sites. The following are the distinct parts of this study: the next section discusses literature followed by creation of hypotheses. This is accompanied by the data interpretation and discussion section. Afterward, this study offers implications for future scholars and practitioner for ongoing expansion and research of geotags. Finally, the paper ends with conclusions.

\footnotetext{
${ }^{*}$ Corresponding author
} 


\section{LITERATURE REVIEW}

\section{Reviews on geotagging in social networking sites use}

The websites for social networking allow users to share different content created by users, such as photography, video, email and other electronic term, these generates positive word-of-mouth. Geotagging is a service which allows the users to publish physical locations and objects that are connected through a digital process (Amitay et al., 2004; Erickson, 2009). Geographical identification metadata information (e.g. images, photos, rich site description (RSS) data, text messages, quick response (QR) codes, etc.) are incorporated into social media data by geotagging strategies (Chong et al., 2018). By the use of geo-tagging technologies, individuals will upload images to SNSs, the location of the tag and the destination of the photo to notify peer groups (Kurashima et al., 2013). Information plays a vital role to minimize the risk significantly and to make decision effectively (Lewis and Chambers, 1999). SNSs would greatly improve the data discovery expertise that help users to conduct the searching process more rapidly and efficiently, optimize and distribute the appropriate shots (Chung et al., 2017). Additionally, geotag usefulness is recognized in order to track global occurrences (Rattenbury et al., 2007) or spatial visualization of tags (Crandall et al., 2009). With the increased use of GPS monitoring systems, users can identify the position and events similar to the user's nearby locations (Zheng et al., 2010). Using SNSs, in general Facebook, users can monitor, personalize, upload and arrange their digital images using geo-tagging technologies (Hampton et al., 2012). It also enhances the exposure of posted images and provides opportunities for further distribution of visual content (Besmer and Lipford, 2010). To create a bridge between this gap, the current research selected users of SNSs using geo-tagging technologies as the target group. Moreover, the Internet has been the most powerful marketing tool for tourism businesses, as tourism has traditionally been considered the leading online retail market (Akehurst, 2009). More recently, social media offers effective and immersive tourism advertising and networking facilities (Zeng and Gerritsen, 2014). Chin et al., (2020) explored that perceived value has appropriately moderated the relationship of destination attractiveness resources and destination images. As a result, the sharing of image and location data using geo-tagging schemes has resulted in new experiences for users of social networking sites. Due to the generation of vast user-generated content (UGC) by geo-tagging technology and its close association with the tourism industry, it is clear that the adoption of geo-tagging technology for tourism experience is being investigated, in particular among users of social networking sites.

This topic is being studied in many information systems and spatial studies owing to emerging technologies. Several researcher from a range of backgrounds focused on spatial photography and the ability to inspire student study in the post-field area (Welsh et al., 2012), population and voluntary location-based information in social media (Haffner et al., 2018), position information in daily life (Rzeszewski and Luczys, 2018), the role of geographical information attainment (Tussyadiah and Zach, 2012). In comparison to other studies , the authors found some studies that investigated the effect of apparent enjoyment, the way users perceive that how easily these technologies can be used, readiness of travelers to incorporate geotagging technologies using the technology adoption model (TAM) (Allam et al., 2012; Chung et al., 2017). Hasan et al. (2020) used theory of planned behavior and explored that the assertiveness, subjective standards and enthusiasm pointedly influence the traveler contentment and domestic tourist behavioral goal. Besides, Haque et al. (2020) integrated personal innovativeness of IT (PIIT) in Unified Theory of Acceptance and Use of Technology (UTAUT) to search the geotagging technology implementation among social networking sites users. They found PIIT accurately describes the personal features of social networking sites users and all constructs except effort expectancy of UTAUT have significant influence on the adoption of geotagging technology among social networking sites users. Haque and Khan (2020) unveiled that technology readiness is an influential element of UTAUT model and the use of geo-tagging technologies has an important effect on users of social networking sites. In comparison, however, the user intention of the SNS users is specifically related to geotagging technology, to the knowledge of the authors. Based on the viewpoints of SNSs users, this broad research vacuum in assimilating the application of geotagging is filled by the current review.

\section{Technology readiness (TR)}

Parasuraman (2000) introduces and describes the conception of technological readiness. This means that, in their everyday social and economic lives, people want to use modern technology. The crucial importance of fashion technology is perceived in business life. Therefore, the technical availability of travelers needs to be assessed using geographic identification techniques. Geotagging technologies enhance the traveler's experience and embrace the vision of travelers for use on different journeys. The importance of technical preparation has become a fundamental phenomenon in the use of innovation and has been studied in several studies. For this reason, Liljander et al. (2006) has confirmed the beneficial effects of the technical preparation using the latest aviation technology. In addition, Kim et al. (2012) examined the importance of technology readiness in hospitality and tourism environments, where customers can be separated from services and services typically depend on service providers. Although some studies have focused on user technology readiness in different contexts, Chen and Li (2010), Mady (2011) and Chung et al. (2017) highlight the availability of travelers, in order to regulate the substantial impact of technological readiness on geotagging conditions of acceptance. This study introduces the technology readiness as a moderator in the UTUAT framework and aims to explore the significant moderation effect of TR in the acceptance of geotagging technology among users of social networking sites.

\section{Research framework and hypotheses}

When travelers enjoy the novel technology and consider it useful for their travel purpose, they will adopt the new technology to enhance their smart tourism experience. Earlier researchers suggested different conceptual models to review relevant to IT/ARE adoption, as well as the Technology Acceptance Model (Davis et al., 1989), IS success Model (DeLone and McLean, 1992), Theory of planned behaviour (Ajzen, 1991), Unified Theory of Acceptance and Use of Technology (UTAUT) (Venkatesh et al., 2003). Among these, UTAUT devised by Venkatesh et al (2003) acknowledged being one amongst the foremost effective model to explain the perceptions of consumers towards the introduction of emerging technologies (Qingfei et al., 2008). In view of UTAUT's robustn ess, this paper followed it as an overarching philosophical construct in order to examine and replenish the void on top of research que ries. Four basic constructs are hypothesized by the theoretical model (Figure 1) developed during this research: Performance Expectancy (PE), Effort Expectancy (EE), Social Influence (SI) and Facilitating Condition (FC). In certain instances, however, only a subset of the UTAUT constructs were implemented by researchers and the possible moderating variables were overlooked (Al-Gahtani et al., 2007; Armida, 2008). Since the primary UTAUT comprises the constructs of PE, EE, SI and FC and offers a comprehensive description to predict the adoption of technology such as SNSs users, additional variables may be needed depending on the particular context of technology usage outside the four key constructs (Marchewka, 2007; Venkatesh et al., 2012; Dwivedi et al., 2017; Hoque and Sorwar., 2017).

\section{Performance expectancy (PE), Effort expectancy and social influence (SI) to Intention to adopt geotagging technology (IAGT)}

Venkatesh et al. (2003) has described that PE is the the extent to which a person feels that using the method would encourage him or her to make improvements in organizational effectiveness and work performance. Venkatesh et al. (2003) has further defined that EE is the 
extent to which a person can easily use the system effectively. The social influence illustrates how a person is influenced to assess by one's own peer groups and the behavior of his or her colleagues or other leading experts of organizations. The social influence controls the way of human behavior to a great extent. A number of researchers found PE, EE and SI are prominent factors of users' behavioral intentions (BIs) in various contexts, i.e. in the implementation of technology in work settings (Venkatesh et al., 2003); adoption of health based information systems (Pai and Huang, 2011); adoption of health (Hoque and Sarwar, 2017), mobile banking adoption (Oliveira et al., 2014); and also acceptance of SNSs for sharing user generated content (UGC) (Herroero et al., 2017). In the case of the implementation of web-based training programs by workers in Jorden, Alrawashdeh et al. (2012) anticipated that EE has a critical effect on the PP. Furthermore, another study (Herrero et al., 2017) projected that Effort Efficiency has substantial influence on Performance expectancy in implementation of SNSs for sharing UGC. The following theory, then, is suggested:

H1: There is a positive impact of Performance Expectancy on the Social Networking Sites users' willingness to accept geotagging technologies.

H2: There is a positive impact of Effort Expectancy on the Social Networking Sites users' willingness to accept geotagging technologies.

H3: Effort Expectancy has a positive influence on the Performance Expectancy of SNSs users to use geotagging technologies

H4: Social Influence has a positive impact on the Social Networking Sites users' intention to adopt geotagging technology.

Facilitating conditions (FC) to Effort expectancy and Intention to adopt geotagging technology (IAGT)

The degree to which a person assumes that there is an organizational and technological framework to facilitate the use of the system is specified by facilitating conditions (FC) (Venkatesh et al., 2003). FC is the valid indicator of use behavior and has been developed by IS/IT research in a number of settings, including adoption of information resources (McKenna et al., 2013); acceptance and use of digital whiteboards (Tosuntas et al., 2015); acceptability of smartphones for health-related services (Oliveira et al., 2014); e-health adoption (Bhattacherjee and Hikmet, 2008). "FC is a direct indicator of EE in the context of e-government" (Dwivedi et al., 2017). This association is also asserted in Australian occupational therapists embracing and using ICTs (Schaper and Pervan, 2007), in Jordanian training programs which were based on the internet (Alrawashdeh et al., 2012) and in Indonesian airlines, e-services were also investigated (Urumsah et al., 2011). We also consider FC to help users quickly comprehend and discover geotagging technologies through these assertions. The hypotheses that can be developed based on this discussion are:

H5. FC has a positive effect on the SNSs users' intention to adopt geotagging technology.

H6. FC has a positive effect on the SNSs users EE of geotagging technology use.

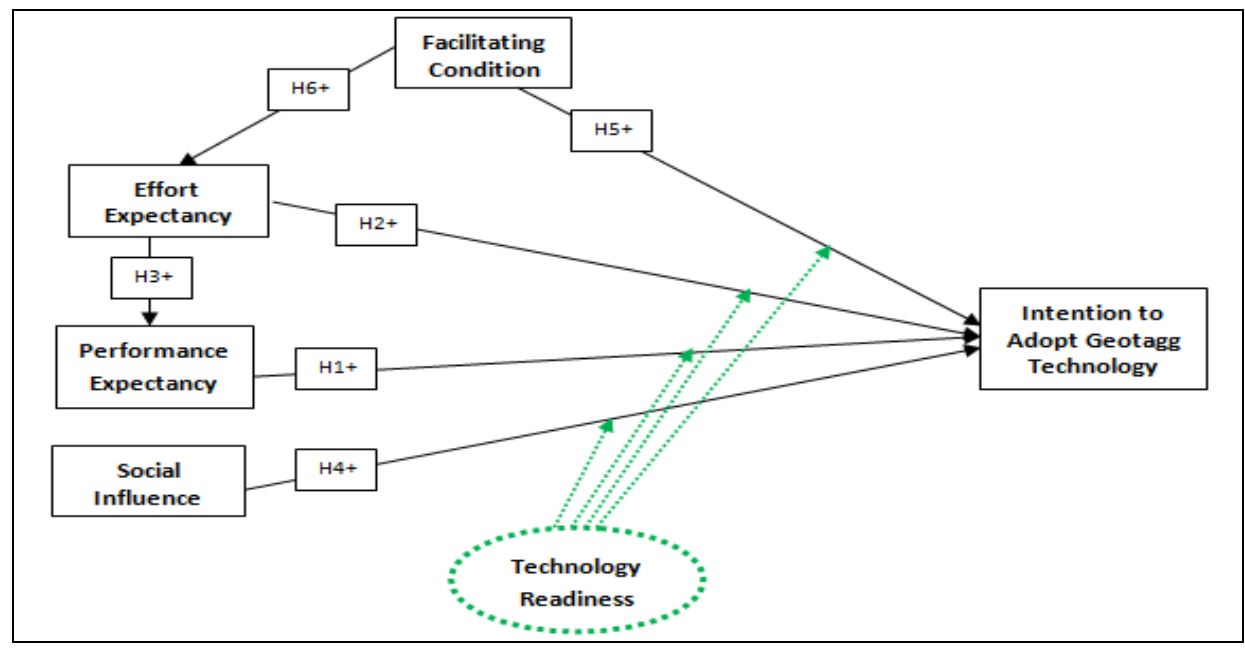

Figure 1. Research Model

The moderating influence of technology readiness

Thus consumers of technology will convey differing views about products and services dependent on technology (Dabholkar, 1996). These paradoxical viewpoints will go along with those from a technical to a technological spectrum (Mick and Fournier, 1998). The word "Technological Readiness" (TR), defined by Parasuraman (2000) as a tendency of using modern technologies to achieve home as well as work objectives. It is a general state of mind composed of multiple workers and intellectual inhibitors who collectively decide if modern technology is appropriate for use (Parasuraman, 2000). The TR model was used in many contexts such as self-service technology (Elliot and Meng, 2009); in construction sectors (Jaafar et al., 2007); in wireless technology (Chor and Kannan, 2006); in internet applications (Taylor et al., 2002). Parasuraman and Colby (2001) observed, owing to their technological preparedness, that technology-based commodity markets are broken down into five segments and that at various times each TR segment entered the industry. In the current research, TR is a key factor in that segments of technology-aided activists can be created for SNS users for tourism with the implementation of geography technology. A significant clarification of why a particular segment of SNS users assigns greater (or lesser) value to a specific function of overt turnout can be found in the values behind any TR segment. TR is a key moderator for the connection between UTAUT variables and the plan to implement geo-tagging technologies. It is proposed that in these partnerships we assume respondents with low or high TR to differ, which indicates the following hypotheses:

H7: The relationship of performance expectancy, effort expectancy, social influence and facilitating condition with intention to adopt geotagging technology exhibited in $\mathrm{H} 1, \mathrm{H} 2, \mathrm{H} 4$ and $\mathrm{H} 5$ will be moderated by Technology readiness of SNSs users for adoption of geotagging technology.

\section{METHODOLOGY}

Research setting

In this research, the target demographic for this empirical review is SNS users' especially the younger citizen of Bangladesh. Since convenience sampling provides cost efficiency, it is commonly used in research into IT systems (Eze et al., 2011). The research even employed a screening 
method for convenience. A substantial part of the study is made up of the younger Bangladeshi people, who are students of various universities (Table 2). They were ideal for tasks such as knowledge seeking and gaming as well as basic communication because of their comfortable use of technology. In addition, respondents were told at all points during the analysis of their rights to revoke their participation (Hoque, 2016).

\section{Measurement}

Earlier reports involve all calculation elements in this study. In order to adapt this study to geotagging technologies in tourism context, the calculation metrics have been tailored. Scales developed by Venkatesh et al. (2003) and Herrero et al. (2017) are adopted to measure the performance expectancy and effort expectancy with three and four items respectively. Social influence and facilitating condition are measured three items each adopted from Venkatesh et al. (2003). Five things developed by Lee et al. (2012) and Parasuraman (2000) have been adapted for calculating technology readiness. The geo-tagging technology intention to adopt is assessed across three objects from Lin and Hsieh (2006) and Davis et al. (1989). Details of the measuring elements and the literature source for each constructs are given in Table 1.

Table 1. Summary of Measurement Items

\begin{tabular}{|c|c|c|}
\hline Construct & Corresponding Items & Items Sources \\
\hline $\begin{array}{l}\text { Performance } \\
\text { expectancy } \\
\text { (PE) }\end{array}$ & $\begin{array}{l}\text { PE1: Geotagging is incredibly useful in distributing smart tourism material in SNSs } \\
\text { PE2: The use of geotagging facilities would increase my performance in the use of intelligent tourism SNSs. } \\
\text { PE3: I can accomplish what is essential to me for intelligent tourism with the geotagging facility of the SNSs. }\end{array}$ & $\begin{array}{l}\text { Venkatesh et al., } 2003 \\
\text { Herrero et al., } 2017\end{array}$ \\
\hline $\begin{array}{l}\text { Effort } \\
\text { expectancy } \\
(\text { EE) }\end{array}$ & $\begin{array}{l}\text { EE1: Geotagging is an easy method to report material for intelligent tourism in SNSs. } \\
\text { EE2: Geotagging is convenient for me that can be used to publish material for intelligent tourism on SNSs. } \\
\text { EE3: It is convenient for me to be able to use geo-tagging technologies } \\
\text { EE4: The use of geo-tagging to report material for the smart tourist activity in SNSs is transparent and easy to understand. }\end{array}$ & $\begin{array}{l}\text { Venkatesh et al., } 2003 \\
\text { Herrero et al. (2017) }\end{array}$ \\
\hline $\begin{array}{l}\text { Social } \\
\text { influence } \\
\text { (SI) }\end{array}$ & $\begin{array}{l}\text { SI1: People who affect my actions are of the view that I should use the geo-tagging service for the smart tourism } \\
\text { experience in SNSs. } \\
\text { SI2: People that holds importance in my life believe that I can use geotagging to smart tourist SNSs } \\
\text { SI3: People whose views I respect choose to use geotagging services in SNSs for the intelligent tourism experience }\end{array}$ & Venkatesh et al., 2003 \\
\hline $\begin{array}{l}\text { Facilitating } \\
\text { conditions } \\
\text { (FC) }\end{array}$ & $\begin{array}{l}\text { FC1: I have the tools required to use geotagging technologies in SNSs for intelligent tourism experience. } \\
\text { FC2: I have the requisite expertise to use geotagging technologies in SNSs for intelligent tourism experience. } \\
\text { FC3: When I have trouble using geotagging for intelligent tourism experience in SNSs, I can get help from others. }\end{array}$ & Venkatesh et al., 2003 \\
\hline $\begin{array}{l}\text { Technology } \\
\text { Readiness } \\
\text { (TR) } \\
\text { Driver }\end{array}$ & $\begin{array}{l}\text { TR1. In general, as it happens, I am the first to learn geotagging technology for intelligent tourism experience in my } \\
\text { circle of friends. } \\
\text { TR2. Without support from others for a smart tourism experience, I will typically find high-tech devices and new facilities. } \\
\text { TR3. I notice that I have fewer issues using geotagging techologies in SNSs for smart tourism experience than other citizens. } \\
\text { TR4. For Smart Tourism experience in SNSs, I recommend using the most advanced geotagging technology available. } \\
\text { TR5. The technology of geotagging allows me greater freedom of mobility. }\end{array}$ & $\begin{array}{l}\text { Parasuraman, } 2000 \\
\text { Lee et al., } 2012\end{array}$ \\
\hline $\begin{array}{l}\text { Intention to } \\
\text { adopt } \\
\text { geotagging } \\
\text { technology } \\
\text { (IAGT) }\end{array}$ & $\begin{array}{l}\text { IAGT1. During SNSs usage, I have high intentions to use geotagging service for smart tourism experience. } \\
\text { IAGT2. I would suggest to my friend the geotagging technology to publish material on SNSs for intelligent } \\
\text { tourism experience } \\
\text { IAGT3. I assume that I will use the geotagging service to publish information on SNSs for smart/intelligent } \\
\text { tourism experience. }\end{array}$ & $\begin{array}{l}\text { Davis et al., } 1989 \\
\text { Lin and Hsieh, } 2006\end{array}$ \\
\hline
\end{tabular}

\section{Questionnaire design and data collection}

The study used a two-part structured questionnaire. Part A includes information on the population, internet and SNSs use, while part B includes measurement elements for the various structures previously validated. The construction indicators are measured by a 7-point Likert scale, with response choices ranging from (1) 'strongly disagree' to (7) 'strongly agree.' The study confirms the recommendation (Roscoe, 1975) that the sample size in the structural equation modeling should be more than 10 times the measurements. The study therefore employed 356 sample sizes, more than ten times that of the measuring elements. The collection of data was carried out between April and May 2019. 370 of the 450 questionnaires distributed, representing an answer rate of $82.22 \%$, were returned. Some 14 questionnaires were excluded because of a lack of information, leading to a total of 356 usable responses.

\section{Data analysis}

Data was compiled into Smart PLS (3.0) applications and entered in Microsoft excel. A computational methodology for interpreting data and a commonly used tool for evaluating the relevance of all proposed model-specific studies with empirical data (Haque et al., 2019) is structural equation modeling (SEM). It gives comprehensive representation of multivariate regression. The relationships between latent constructions and estimation, calculated by various metrics, is typically discussed. "The path model is a large version of multiple regression model where different multiple regressions are concurrently measured.” (Cohen et al., 2013).

\section{RESULTS AND DISCUSSIONS}

\section{Demographic profile of sample}

Demographics represent the male are major part of sample $60 \%$ (215) than female $40 \%$ (141). It exhibits the socio-economic aspect of Bangladesh where males are more active participant to survey than female. Considering the academic data of the survey, it is explored that in terms of the academic qualifications $320(90 \%)$ attained bachelor degrees; $22(6 \%)$ attained Higher secondary degree; $5(1 \%)$ attained master degrees; $5(1 \%)$ attained below higher secondary degrees, $2(1 \%)$ attained Ph.D. and $2(1 \%)$ attained others degree. Based on age group, 282 (79\%) of them were between 20 and 30 years years old, $50(14 \%)$ under 20 years old, $20(6 \%)$ between 31 and forty years old, and $3(1 \%)$ between 41 and 50 years old. As far as social networking sites (SNSs) use experience, $41 \%$ has $1-3$ years SNSs use experience which is followed by 34\% who have 4- 6 years SNSs use experience. On the other hand, $15 \%$ have more than 7 years SNSs use experience and $10 \%$ have less than one-year use experience. One or more SNS channels may be used by each participant and hardware in the case of SNSs and their hardware. Therefore, the column frequency is greater than the sample. A majority of people interviewed in the survey used Facebook (38\%) in Bangladesh, followed by YouTube $28 \%$, and Google+ $11 \%$. In case of hardware use most of respondents use (60\%) use smartphone followed by laptop $20 \%$ and desktop $12 \%$ (Table 2). While interpretating the data, demographic variables were viewed as control variable.

\section{Measurement model}

Bagozzi et al. (1991) claimed that before the hypothesized relationship was investigated internal reliability and convergent significance of the measurement model must be checked. In order to test internal reliability, composite reliability and Cronbach alpha have been commonly used. In order to meet the internal reliability, composite reliability and alpha Cronbach should have a value above 0.70 . 
"Convergent validity is considered to be satisfactory when measurement constructs have an average variance extracted (AVE) of at least 0.50 and items loading are above 0.70" (Hair et al., 1995). Table 3 depicted the alpha of Cronbach, the average variance extracted (AVE) and the composite reliability, while Table 4 for each construct indicated the item loading in bold format.

Table 2. Profile of the Respondents

\begin{tabular}{|c|c|c|c|}
\hline Variable & Description & Frequency & Percentage \\
\hline \multirow{2}{*}{ Gender } & Male & 215 & $60 \%$ \\
\hline & Female & 141 & $40 \%$ \\
\hline \multirow{6}{*}{ Age(years) } & Below 20 years & 110 & $31 \%$ \\
\hline & $20-30$ years & 222 & $62 \%$ \\
\hline & $31-40$ years & 20 & $6 \%$ \\
\hline & $41-50$ years & 3 & $1 \%$ \\
\hline & $51-60$ years & 0 & $0 \%$ \\
\hline & Above 60 years & 1 & $0 \%$ \\
\hline \multirow{6}{*}{ Education level } & Below Higher Secondary & 5 & $1 \%$ \\
\hline & Higher secondary & 22 & $6 \%$ \\
\hline & Bachelors & 320 & $90 \%$ \\
\hline & Masters & 5 & $1 \%$ \\
\hline & Ph.D. & 2 & $1 \%$ \\
\hline & Others & 2 & $1 \%$ \\
\hline \multirow{8}{*}{ Social Networking Platform } & Facebook & 470 & $38 \%$ \\
\hline & You tube & 348 & $28 \%$ \\
\hline & Google+ & 136 & $11 \%$ \\
\hline & LinkedIn & 31 & $3 \%$ \\
\hline & Twitter & 105 & $8 \%$ \\
\hline & Pinterest & 8 & $1 \%$ \\
\hline & All & 50 & $4 \%$ \\
\hline & Other & 89 & $7 \%$ \\
\hline \multirow{6}{*}{ Hardware use } & Smartphone & 511 & $60 \%$ \\
\hline & Laptop & 173 & $20 \%$ \\
\hline & Desktop & 102 & $12 \%$ \\
\hline & Tablet & 11 & $1 \%$ \\
\hline & All & 29 & $4 \%$ \\
\hline & Other & 23 & $3 \%$ \\
\hline \multirow{5}{*}{$\begin{array}{l}\text { SNSs use Experience } \\
\text { (Years) }\end{array}$} & Less than 1 year & 37 & $10 \%$ \\
\hline & $1-3$ years & 145 & $41 \%$ \\
\hline & $4-6$ years & 122 & $34 \%$ \\
\hline & $7-9$ years & 46 & $13 \%$ \\
\hline & More than 9 years & 6 & $2 \%$ \\
\hline
\end{tabular}

Table 3. Measurement Model

\begin{tabular}{|l|c|c|c|}
\hline Constructs & Cronbach's Alpha & Composite Reliability & Average Variance Extracted (AVE) \\
\hline Intention to adopt geotagging technology & 0.921 & 0.950 & 0.864 \\
\hline Effort Expectancy & 0.932 & 0.952 & 0.831 \\
\hline Facilitating conditions & 0.906 & 0.941 & 0.842 \\
\hline Performance Expectancy & 0.931 & 0.956 & 0.879 \\
\hline Social Influence & 0.930 & 0.956 & 0.878 \\
\hline
\end{tabular}

Table 4. Cross Loadings

\begin{tabular}{|l|l|l|l|l|l|}
\hline & IAGT & EE & FC & PE & SI \\
\hline IAGT1 & $\mathbf{0 . 9 3 1}$ & 0.536 & 0.518 & 0.581 & 0.573 \\
\hline IAGT2 & $\mathbf{0 . 9 2 1}$ & 0.526 & 0.517 & 0.595 & 0.537 \\
\hline IAGT3 & $\mathbf{0 . 9 3 6}$ & 0.569 & 0.542 & 0.608 & 0.572 \\
\hline EE1 & 0.544 & $\mathbf{0 . 9 2 2}$ & 0.734 & 0.747 & 0.684 \\
\hline EE2 & 0.522 & $\mathbf{0 . 9 1 4}$ & 0.678 & 0.753 & 0.673 \\
\hline EE3 & 0.573 & $\mathbf{0 . 9 0 7}$ & 0.706 & 0.726 & 0.694 \\
\hline EE4 & 0.494 & $\mathbf{0 . 9 0 4}$ & 0.710 & 0.708 & 0.683 \\
\hline FC1 & 0.522 & 0.733 & $\mathbf{0 . 9 2 0}$ & 0.637 & 0.630 \\
\hline FC2 & 0.501 & 0.717 & $\mathbf{0 . 9 1 9}$ & 0.595 & 0.640 \\
\hline FC3 & 0.534 & 0.684 & $\mathbf{0 . 9 1 3}$ & 0.640 & 0.656 \\
\hline PE1 & 0.604 & 0.734 & 0.616 & $\mathbf{0 . 9 3 6}$ & 0.687 \\
\hline PE2 & 0.625 & 0.754 & 0.644 & $\mathbf{0 . 9 4 3}$ & 0.700 \\
\hline PE3 & 0.571 & 0.775 & 0.652 & $\mathbf{0 . 9 3 4}$ & 0.703 \\
\hline SI1 & 0.554 & 0.678 & 0.671 & 0.685 & $\mathbf{0 . 9 3 0}$ \\
\hline SI2 & 0.552 & 0.722 & 0.632 & 0.689 & $\mathbf{0 . 9 3 8}$ \\
\hline SI3 & 0.588 & 0.706 & 0.661 & 0.714 & $\mathbf{0 . 9 4 2}$ \\
\hline
\end{tabular}

Legend: IAGT = Intention to adopt geotagging technology; EE= Effort Expectancy;

$\mathrm{FC}=$ Facilitating conditions; $\mathrm{PE}=$ Performance Expectancy; SI= Social Influence

Cronbach's alpha values were between 0.906 and 0.932 , and their composite reliability ranged between 0.941 and 0.956 , which satisfy internal reliability requirements. The load value is between 0.904 and 0.943 , and the AVE is between 0.831 and 0.879 , which mean the load value is above the mentioned level. The apparent variables thus follow the convergent criterion for validity (Biswas et al., 2020).

On the other hand, the discriminant validity was tested using two measures. First, "the correlations among constructs should be below the cut-off of 0.85" (Biswas, 2005). Second, "the square root of AVE should exceed the correlations of a construct with other latent constructs in the model" (Fornell and Larcker, 1981). The program values show that the square root of AVE was higher than the respective correspondence and that all the correlations between latent structures were below the cut-off point of 0.85 (Table 5). This indicated that the requirements for discriminant validity should be achieved and that the study model follows the requirements for the measurement model. 


\section{STRUCTURAL MODEL}

\section{Assessment of variance explanation through research model}

The study found that research model significantly explains the variance. Figure 2 shows the $\left(\mathrm{R}^{2}\right)$ explanation power for each dependent variable. $\mathrm{R}^{2}$ value implies the percentage of total variance of the dependent variable explained by the independent variable. This research found that the predicting power $\left(\mathrm{R}^{2}\right)$ of dependent variable such as intention to adopt geotagging technology was 0.458 , performance expectancy 0.647 and effort expectancy was 0.601 . All $\mathrm{R}^{2}$ value exceeds the recommended cut of criterion of $10 \%$ proposed by Falk and Miller (1992). So our model explains $45.8 \%$ of the variance in the intention to adopt geotagging technology, $64.7 \%$ variance in performance expectancy and $60.1 \%$ of variance of effort expectancy in adoption of geotagg among SNSs users for smart tourism experience. Furthermore, we also checked predictive relevance (Q2) to examine the substantive effect of our research model.

Table 5. Correlation matrix, Square root of AVE

\begin{tabular}{|l|c|c|c|c|c|}
\hline & IAGT & EE & FC & PE & SI \\
\hline IAGT & $\mathbf{0 . 9 3 0}$ & & & & \\
\hline EE & 0.585 & $\mathbf{0 . 9 1 2}$ & & & \\
\hline FC & 0.566 & 0.775 & $\mathbf{0 . 9 1 8}$ & & \\
\hline PE & 0.640 & 0.804 & 0.680 & $\mathbf{0 . 9 3 8}$ & \\
\hline SI & 0.603 & 0.750 & 0.699 & 0.743 & $\mathbf{0 . 9 3 7}$ \\
\hline
\end{tabular}

Table 6. Predictive Relevance

Legend: IAGT= Intention to adopt geotagging technology; EE= Effort Expectancy; FC= Facilitating conditions; PE= Performance Expectancy; SI= Social Influence

Other statistical analysis was conducted to explore its statistical significance (Q2). Cohen's (1988) indicated 0.02 is a 'tiny,' 0.15 represented a 'medium,' and 0.'35 was a 'large' impact. The intention to adopt geotagging $(\mathrm{Q} 2=0.376)$, the performance expectancy $(\mathrm{Q} 2=0.5434$ and the effort expectancy $(\mathrm{Q} 2=0.476)$ was suggested in our model to be high in effect. The predictive validity of this model has also been verified (Table 6). Furthermore, we investigated the significant impact of our test model for Cohen's (1988) effect size (f2). It is defined as "the degree to which the phenomenon is present in population." Cohen's (1988) suggested $\mathrm{f} 2$ values of $0.02,0.15$, and 0.35 are small, medium, and large, respectively. Thus, our model suggests that intention to adopt geotagging technology (f2 $=0.125)$, had small effect sizes, whereas performance expectancy ( $\mathrm{f} 2=1.834)$ and effort expectancy $(\mathrm{f} 2=1.508)$ had a large effect size.

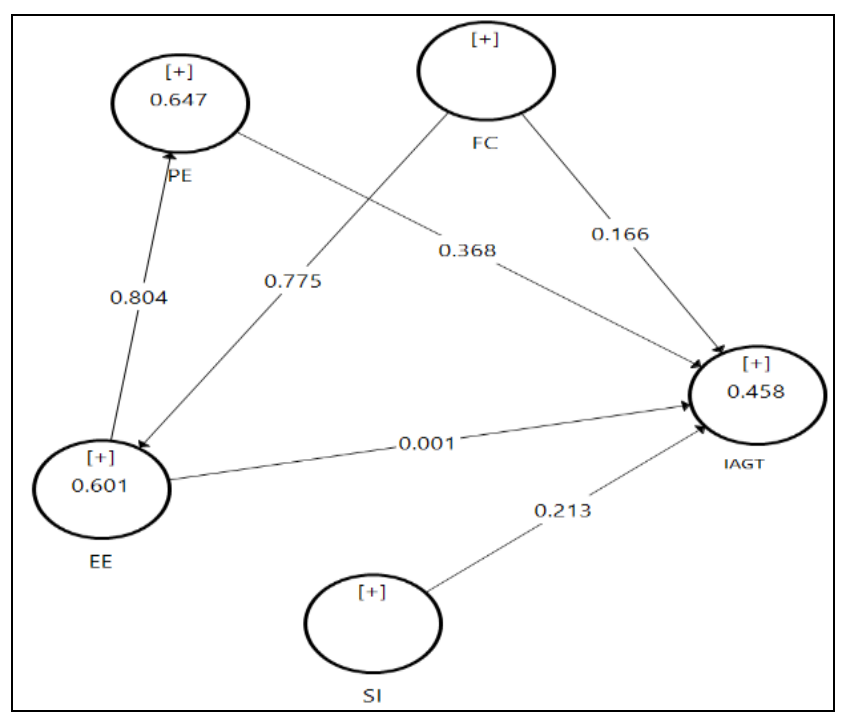

Figure 2. Validated research model for Geotagg adoption

\section{Hypotheses results and discussion}

The thesis used Smart PLS 3.0 to evaluate the connections between the various components of the proposed models of research. Figure 2 displays both trajectory coefficients. The findings in hypotheses suggest that the performance expectancy of the geotagging technology is a good impact $(\beta=0.368, \mathrm{t}=4.681, \mathrm{p}<0.001)$ on intention to adopt geotagging technology, so $\mathrm{H} 1$ can not be dismissed. While geotagging technology uses much of the time to upload images and exchange locations with users of SNSs, it focuses more on the useful aspects. This conclusion is close to other analyses of technology adoption, such as adoption of geotagging technology (Haque et al., 2020; Haque and Khan 2020). Hypothesis 4 is known because the social influence also suggest significant impact on intention to adopt geotagging technology $(\beta=$ $0.213, \mathrm{t}=2.508, \mathrm{p}<0.05$ ). This data reflects Bangladesh's socio economic situation, with the bulk of the population affected by their employers, peers and others. This finding was decided on with UTAUT's SNS sharing application (Herrero et al., 2017). This finding was accepted.

Facilitating condition has a favorable effect on the intention to adopt geotagging technology because statistically meaningful effects are obtained with the program $(\beta=0.166, \mathrm{t}=2.358, \mathrm{p}<0.05)$, so we acknowledge H5. These results are relevant to the Haque et al. (2020) findings, which showed that facilitationg condition are directly affected to adopt geotagging technology. The research suggested two new directions among explanatory UTAUT variables ( e.g. pefromance expectancy to effort expectancy (H3) and effort expectancy to facilitating condition (H5), separate from orginial UTAUT model (Venkatesh et al., 2003). For both proposed relationships $(\beta=0,804 ; \mathrm{t}=26,653 ; \mathrm{p}<$ $0,001$; and $\beta=0,765, \mathrm{t}=24,500 ; \mathrm{p}<0,001)$ methodological research resulted in statistically relevant values. Then hypothesis 3 and hypothesis 5 are firmly endorsed. Interestingly, new proposed path between the predictor variables such as facilitating condition to effort expectancy was significant in adoption of geotagging technology among the SNSs user for tourism experience. This finding is consistent with other IT adoption studies in different contexts (e.g. Alrawashdeh et al., 2012; Dwevedi et al., 2017; Urumsah et al., 2011 Schaper and Pervan, 2007). More interestingly, the acceptance of the geotagging technologies among SNS users is also important in the other proposed route between two explanatory UTAUT variables, such effort expectancy to performance expectancy. These findings are similar to Chung et al. (2017), where performance expectancy of use has an impact on perceived utility (root variable of perfromance expectancy). But the 
predicted effect of effort expectancy on geotagging purpose was not explicitly optimistic $(\beta=0.002, \mathrm{t}=0.010, \mathrm{p}<0.05)$. H2 has not however been sponsored. However, this has indirectly influenced the purpose of geotagging technology by success standards (Table 7 for details). The findings indicate that performance expectancy has a greater impact than effort expectancy on the decision to adopt geotagging technology. This result, which coincides with the acceptance of the UTAUT application (Hoque and Sarwar, 2017), typically has greater repercussions than effort.

Table 7. Structural relationships

\begin{tabular}{|c|c|c|c|c|c|}
\hline Hypothesis & Relationship & Std. Beta & T Statistics & P Values & Comments \\
\hline H1 & PE -> BI & 0.368 & $4.681^{* * *}$ & 0.000 & Supported \\
\hline H2 & EE -> BI & 0.001 & 0.010 & 0.992 & Not Supported \\
\hline H3 & EE -> PE & 0.804 & $26.653^{* * *}$ & 0.000 & Supported \\
\hline H4 & SI -> BI & 0.213 & $2.508^{*}$ & 0.012 & Supported \\
\hline H5 & FC -> BI & 0.166 & $2.358^{*}$ & 0.019 & Supported \\
\hline H6 & FC -> EE & 0.775 & $24.500^{* * *}$ & 0.000 & Supported \\
\hline \multicolumn{7}{|c|}{ Legend: p: significance: *p<0.05;** p<0.01; ***p<0.001 } \\
\hline
\end{tabular}

Table 8. Moderating effect of Geotags use frequency

\begin{tabular}{|c|c|c|c|}
\hline Path & Std. Beta & t-statistics & Decision \\
\hline PE* TR-> IAGT & 0.095 & 2.694 & Moderated \\
\hline EE* TR -> IAGT & 0.055 & 1.967 & Moderated \\
\hline SI* TR -> IAGT & 0.098 & 2.372 & Moderated \\
\hline FC* TR -> IAGT & -0.013 & 0.397 & Not Moderated \\
\hline
\end{tabular}

\section{Moderating effect of SNSs users Technology Readiness}

In the analysis the moderation impact of the metric variables was tested using Smart PLS 3.0. In order to do so, we analyzed the association effect on the outcome variable of the moderating variable and the independent one. For PE, EE, SI, and FC the analysis was carried out separately as the preparation for SNS's users to take geotagging technologies differently moderates their relationship. The interaction effect of performance expectancy and SNSs user technology readiness (PE $\times$ TR) on intention to adopt geotagging technology is statistically significant $(\beta=0.095, \mathrm{t}=2.694, \mathrm{p}<0.05)$. The product effect of effort expectancy and SNSs user's technology readiness $(\mathrm{EE} \times$ TR) on intention to adopt geotagging technology is also statistically significant $(\beta=0.055, \mathrm{t}=1.967, \mathrm{p}<0.05)$. Significant interaction effect of SI and SNSs user's technology readiness (SI $\times$ TR) on intention to adopt geotagging technology $(\beta=0.098, \mathrm{t}=2.372, \mathrm{p}<0.05)$ was also attained. Finally, the interaction effect of facilitating condition and SNSs user's technology readiness $(\mathrm{FC} \times \mathrm{TR})$ on intention to adopt geotagging technology is not statistically significant $(\beta=-0.013, \mathrm{t}=0.397, \mathrm{p}>0.05)$ (Table 8 for details).

Most importantly, SNSs users' technology readiness significantly moderates the different interrelationship of PE, EE and SI with willingness to adopt geotagging technology. These results are concurrent with many other research findings Borrero et al. (2014) where they found technology readiness moderates the social and psychological factors to adopt SNSs for student's movement. These findings also confirm the outcome of (Lin and Chang, 2011; Dabholkar and Bagozzi, 2002) where they found moderating effect of TR in different IS/IT adoption studies. Therefore, technology readiness can be conceptualized as a moderator of UTAUT to adopt the technology at individual level and adoption of geotagging technology for smart tourism experience.

\section{Theoretical and managerial contributions}

This research has important implications for philosophy and management. In the first instance, the research extended SNS's users technology readiness as moderator in the Unified theory of acceptance and use of technology. The study introduced association between two explanatory variables of UTAUT namely effort expectancy and performance expectancy and found strong empirical evidence regarding this association. Moreover, it also proved that there is an interrelationship between two predicting variables of UTAUT model namely FC and EE. These will enrich the model and add new aspect for future knowledge. This strengthens the model and introduces additional elements of future awareness. This study, on the other hand, will direct decision makers from the tourism industry regarding the numerous geotagging factors that impact SNS users in smart tourism experiences. Finally, this study will provide appropriate policy making indications to SNSs service providers regarding the acceptance and use of geotagging for smart tourism experience.

\section{LIMITATIONS, FUTURE RESEARCH DIRECTIONS AND CONCLUSIONS}

This research is not free from weaknesses. The research employed non-random sampling methods, including convenience sampling. Random sampling methods may be used in forthcoming studies. The study used cross-sectional details. For prospective investigators, longitudinal evidence may be used to clarify the phenomenon in greater detail. The students were the target demographic of the study. Future studies will combine both classes of individuals, which further generalizes findings. After all, this study used the Unified theory of acceptance and use of technology (UTAUT) paradigm to clarify the purpose of SNS users to implement geotagging technology for intelligent tourism. It analyzed the performance expectancy; social influence and facilitating conditions are significant precedents for the implementation among SNS users of geotagging technology for tourism purposes.

It also found that facilitating condition prominently affect the effort expectancy and effort expectancy properly affect the performance expectancy of UTAUT model for adoption of geotag technology among the SNSs users. It presents the socio-economic status of Bangladesh where people believe that proper infrastructure of information technology will enhance the uses of technology. It also discussed readiness to use technology as a vital moderator for SNSs users' smart tourism experience for implementation of geotagging technology. The outcome of this study will offer significant itinerary for future scholars. It also guides the decision makers of tourism industry in designing the appropriate policy for adoption of geotagging technology for smart tourism experience.

\section{REFERENCES}

Alrawashdeh, T.A. (2012). Factors Affecting Acceptance of Web-Based Training System: Using Extended UTAUT and Structural Equation Modeling. International Journal of Computer Science, Engineering and Information Technology, 2(2), 45-54. https://doi.org/10.5121/ijcseit.2012.2205

Allam, H., Blustein, J., Bliemel, M., \& Spiteri, L. (2012). Exploring factors impacting users' attitude and intention towards social tagging systems. Paper Presented at the $45^{\text {th }}$ Hawaii International Conference on System Science. https://doi.org/10.1109/HICSS.2012.267

Al-Gahtani, S.S., Hubona, G.S., \& Wang, J. (2007). Information Technology (IT) in Saudi Arabia: Culture and the Acceptance and Use of IT. Information \& Management, 44(8), 681-691. https://doi.org/10.1016/j.im.2007.09.002

Ajzen, I. (1991). The theory of planned behavior. Organizational Behavior and Human Decision Processes, 50(2), $179-211$.

Amitay, E., Har'El, N., Sivan, R., \& Soffer, A. (2004). Web-a-where: geotagging web content, in: Proceedings of the 27th Annual International Conference on Research and Development in Information Retrieval - SIGIR '04. Presented at the 27th annual international conference, ACM Press, Sheffield, United Kingdom, p. 273. https://doi.org/10.1145/1008992.1009040

Akehurst, G. (2009). User generated content: the use of blogs for tourism organisations and tourism consumers. Service Business, 3(1), 51-61. https://doi.org/10.1007/s11628-008-0054-2

Armida, E. (2008). Adoption Process for VOIP: The Influence of Trust in the UTAUT Model, Unpublished Ph.D. Dissertation, Purdue University.

Besmer, A., \& Richter Lipford, H. (2010). Moving beyond untagging: Photo privacy in a tagged world. In Proceedings of the SIGCHI Conference on Human Factors in Computing Systems, 1563-1572. https://doi.org/10.1145/1753326.1753560 
Bhattacherjee, A., \& Hikmet, N. (2008). Reconceptualizing organizational support and its effect on information technology usage: evidence from the health care sector. Journal of Computer Information Systems, 48(4), 69-76, https://doi.org/10.1080/08874417.2008.11646036

Biswas, C., Deb, S.K., Hasan, A.A.T., \& Khandakar, M.S.A. (2020). Mediating effect of tourists' emotional involvement on the relationship between destination attributes and tourist satisfaction. Journal of Hospitality and Tourism Insights. https://doi.org/10.1108/jhti-05-2020-0075

Borrero, J.D., Yousafzai, S.Y., Javed, U., \& Page, K.L. (2014). Expressive participation in Internet social movements: Testing the moderating effect of technology readiness and sex on student SNS use. Computers in Human Behavior, 30, 39-49. https://doi.org/10.1016/j.chb.2013.07.032

Chang, A.M., \& Kannan, P.K. (2006). Employee technology readiness and adoption of wireless technology and services. In Proceedings of the 39th Annual Hawaii International Conference on System Sciences (HICSS'06), 2, 42c-42c, IEEE. https://doi.org/10.1109/HICSS.2006.148

Chen, S., \& Li, S. (2010). Consumer adoption of e-service: Integrating technology readiness with the theory of planned behavior. African Journal of Business Management, 4(16), 3556-3563. https://doi.org/10.5897/AJBM.9000149

Chin, Y.S., Mohamad, A.A., Lo, M.C., Ibrahim, W.H.W., \& Ha, S.T., (2020). Antecedents of destination image in natural protected area: The moderating role of perceived value. GeoJournal of Tourism and Geosites, 32(4), 1222-1228. https://doi.org/10.30892/gtg.32405-561

Chong, W.K., Naganathan, H., Liu, H., Ariaratnam, S. \& Kim, J. (2018). Understanding infrastructure resiliency in Chennai, India using twitter's geotags and texts: A preliminary study. Engineering, 4(2), 218-223. https://doi.org/10.1016/j.eng.2018.03.010

Chung, N., Tyan, I., \& Han, H. (2017). Enhancing the smart tourism experience through geotag. Information Systems Frontiers, 19, 731-742. https://doi.org/10.1007/s10796-016-9710-6

Crandall, D.J., Backstrom, L., Huttenlocher, D., \& Kleinberg, J. (2009). Mapping the world's photos. Proceedings of the 18th International Conference on World Wide Web, 761-770. https://doi.org/10.1145/1526709.1526812

Cohen, J. (1988). Statistical power analysis for the behavioral sciences. Mahwah, NJ: Lawrence Erlbaum.

Dwivedi, Y.K., Rana, N.P., Janssen, M., Lal, B., Williams, M.D. \& Clement, M. (2017). An empirical validation of a unified model of electronic government adoption (UMEGA). Government Information Quarterly, 34(2), 211-230. https://doi.org/10.1016/j.giq.2017.03.001

Davis, F.D., Bagozzi, R.P., \& Warshaw, P.R. (1989). User acceptance of computer technology: A comparison of two theoretical models. Journal of Management Science. 35(8), 982-1003. https://doi.org/10.1287/mnsc.35.8.982

Dabholkar, P. (1996). Consumer evaluations of new technology-based self-service options: An investigation of alternative models of service quality. International Journal of Research in Marketing, 13(1), 29-51. https://doi.org/10.1016/0167-8116(95)00027-5

DeLone, W.H., \& McLean, E.R. (1992). Information systems success: The quest for the dependent variable. Information Systems Research, 3(4), 60-95. https://doi.org/10.1287/isre.3.1.60

Dabholkar, P.A., \& Bagozzi, R.P. (2002). An attitudinal model of technology-based self-service: Moderating effects of consumer traits and situational factors, Journal of the Academy of Marketing Science, 30 (3), 184-201. https://doi.org/10.1177/0092070302303001

Elliot, M., \& Meng, J. (2009). Assessing Chinese consumers' likelihood to adopt self-service technologies. International Business \& Economics Research Journal, 8(2), 27-40. https://doi.org/10.19030/iber.v8i2.3099

Erickson, I. (2009). Locative technologies and the organization of place and space. Paper presented at the American Sociological Association Annual Conference, San Francisco, CA.

Eze, U.C., Goh, M.H., Ling H.Y., \& Lee, C.H. (2011). Intention to use e-government services in Malaysia: Perspective of individual users. In: Informatics engineering and information science, 512-526. http://dx.doi.org/10.1007/978-3-642-25453-6_43

Falk, R.F., \& Miller, N.B., (1992). A Primer for Soft Modeling. University of Akron Press.

Fornell, C., \& Larcker, D.F. (1981). Evaluating structural equation models with unobservable variables and measurement error. Journal of Marketing Research, 18(1), 39-50. https://doi.org/10.1177/002224378101800104

Hair, Jr. JF, Anderson RE, Tatham RL \& William C. (1995). Multivariate data analysis with readings. New Jersy, Prentice Hall.

Hampton, K.N., Goulet, L.S., Marlow, C., \& Rainie, L. (2012). Why most Facebook users get more than they give. Pew Research Center's Internet and American Life Project, accessed October 25, 2019. http://www.pewinternet.org/ /media//Files/Reports/2012/PIP_Facebook \%20users_2.3.12.pdf

Haffner, M., Mathews, A.J., Fekete, E., \& Finchum, G.A. (2018). Location-based social media behavior and perception: Views of university students. Geographical Review, 108 (2), 203-224. https://doi.org/10.1111/gere.12250

Haque, M.Z., Qian, A., \& Akther, T. (2019). Investigating the Impact of Environmental and Organizational Factors on the Adoption of Social Networking Sites (SNSs). Journal of Business, 4(1), 17-28. https://doi.org/10.18533/job.v4i1.118

Haque, M.Z., Qian, A., Amin, M., \& Islam,T. (2020). An Empirical Study on Geotagging Technology Adoption Among the Social Networking Sites (SNSs) Users: The Moderating Efect of Geotagg's Use Frequency. Journal of Information \& Knowledge Management, 19(3), 2050018. https://doi.org/10.1142/S0219649220500185

Haque, M.Z., \& Khan, R.H. (2020). Adoption of Geotagging Technology for Tourism Experience: A Study on Social Networking Sites' Users. Journal of Business Administration, 41(1), 53-73.

Hasan, A.A., Biswas, C., Roy, M., Akter, S., \& Kuri, B.C. (2020). The Applicability of Theory of Planned Behaviour To Predict Domestic Tourist Behavioural Intention: The Case of Bangladesh. GeoJournal of Tourism and Geosites, 31(3), 1019-1026. https://doi.org/10.30892/gtg.31313-536

Hoque, M.R. (2016). An empirical study of mHealth adoption in a developing country: the moderating effect of gender concern. BMC Medical Informatics and Decision Making 16(1), 1-10. https://doi.org/10.1186/s12911-016-0289-0

Hoque, R. \& Sorwar, G. (2017). Understanding factors influencing the adoption of mHealth by the elderly: An extension of the UTAUT model. International Journal of Medical Informatics, 101, 75-84. https://doi.org/10.1016/j.ijmedinf.2017.02.002

Herrero, Á., San Martín, H. \& Garcia-De los Salmones, M. del M., (2017). Explaining the adoption of social networks sites for sharing user-generated content: A revision of the UTAUT2. Computers in Human Behavior, 71(c), 209-217. https://doi.org/10.1016/j.chb.2017.02.007

Hu, L.T., \& Bentler, P.M. (1999). Cutoff criteria for fit indexes in covariance structure analysis: Conventional criteria versus new alternatives. Structural equation modeling: a multidisciplinary journal, 6(1), 1-55. https://doi.org/10.1080/10705519909540118

Jaafar, M., Aziz, A.R.A., Ramayah, T., \& Saad, B. (2007). Integrating information technology in the construction industry: Technology readiness assessment of Malaysian contractors. International Journal of Project Management, 25(2), 115-120. https://doi.org/10.1016/j.ijproman.2006.09.003

Junglas, I.A., \& Watson, R.T. (2008). Location-based services. Communications of the ACM, 51(3), 65-69. https://doi.org/10.1145/1325555.1325568

Junglas, B. (2014). Measuring tourist activities in cities using geotagged photography. Tourism Geographies, 16(1), 88-104. https://doi.org/10.1080/14616688.2013.868029

Kim, A.J., \& Johnson, K.K.P. (2016). Power of consumers using social media: Examining the influences of brand-related user-generated content on Facebook. Computers in Human Behavior, 58(c), 98-108. https://doi.org/10.1016/j.chb.2015.12.047

Kim, J.S., Christodoulidou, N., \& Brewer, P. (2012). Impact of individual differences and consumers' readiness on likelihood of using self-service technologies at hospitality settings. Journal of Hospitality \& Tourism Research, 36(1), 85-114. https://doi.org/10.1177/1096348011407311

Kline, R.B. (2005). Principles and Practice of Structural Equation Modeling, Guilford Publications.

Kurashima, T., Iwata, T., Irie G., \& Fujimura, K. (2013). Travel route recommendation using geotagged photos. Knowledge and Information Systems, 37(1), 37-60. https://doi.org/10.1007/s10115-012-0580-Z

Lee, Y.K., Park, J.H., Chung, N., \& Blakeney, A. (2012). A unified perspective on the factors influencing usage intention toward mobile financial services. Journal of Business Research, 65(11), 1590-1599. https://doi.org/10.1016/j.jbusres.2011.02.044

Lewis, R.C., \& Chambers, R.E. (1999). Marketing leadership in hospitality: Foundations and practices. John Wiley and Sons, New York.

Liljander, V., Gillberg, F., Gummerus, J., \& van Riel, A. (2006). Technology readiness and the evaluation and adoption of self-service technologies. Journal of Retailing and Consumer Services, 13(3), 177-191. https://doi.org/10.1016/j.jretconser.2005.08.004

Lin, J.C., \& Chang, H. (2011). The role of technology readiness in self-service technology acceptance. Managing Service Quality: An International Journal, 21(4), 424-444. https://doi.org/10.1108/09604521111146289

Lin, J.S.C., \& Hsieh, P. (2006). The role of technology readiness in customers' perception and adoption of self-service technologies. International Journal of Service Industry Management, 17(5), 497-517. https://doi.org/10.1108/09564230610689795 
Luo, J., Joshi, D., Yu, J., \& Gallagher, A. (2011). Geotagging in multimedia and computer vision-a survey. Multimedia Tools and Applications, 51, 187-211. https://doi.org/10.1007/s11042-010-0623-y

Mady, T.T. (2011). Sentiment toward marketing: should we care about consumer alienation and readiness to use technology? Journal of Consumer Behaviour, 10(4), 192-204. https://doi.org/10.1002/cb.329

McKenna, B., Tuunanen,T., \& Gardner, L. (2013). Consumers' adoption of information services. Information \& Management, 50(5), 248-257. https://doi.org/10.1016/j.im.2013.04.004

McLaughlin, C., \& Vitak, J. (2012). Norm evolution and violation on Facebook. New Media \& Society, 14(2), 299-315. https://doi.org/10.1177/1461444811412712

Marchewka, J.T, Liu C., \& Kostiwa K. (2007). An application of the UTAUT model for understanding student perceptions using course management software. Communications of the IIMA, 7(2), 93-104.

Mick, D.G., \& Fournier, S. (1998). Paradoxes of technology: Consumer cognizance, emotions and coping strategies. Journal of Consumer Research, 25(2), 123-147. https://doi.org/10.1086/209531

Öz, M. (2015). Social media utilization of tourists for travel-related purposes. International Journal of Contemporary Hospitality Management, 27(5), 10031023. https://doi.org/10.1108/IJCHM-01-2014-0034

Oliveira, T., Faria, M., Thomas. M.A., \& Popovic, A. (2014). Extending the understanding of mobile banking adoption: When UTAUT meets TTF and ITM. International Journal of Information Management, 34(5), 689-703. https://doi.org/10.1016/j.ijinfomgt.2014.06.004

Pai, F.Y., \& Huang, K.I. (2011). Applying the Technology Acceptance Model to the introduction of healthcare information systems. Technological Forecasting and Social Change, 78(4), 650-660. https://doi.org/10.1016/j.techfore.2010.11.007

Parasuraman, A. (2000). Technology readiness index (TRI): A multiple-item scale to measure readiness to embrace new technologies. Journal of Service Research, 2(4), 307-20. https://doi.org/10.1177/109467050024001

Parasuraman, A., \& Colby, C. (2001). Techno-ready marketing: How and why your costumers adopt technology. New York: The Free Press.

Qingfei, M, Shaobo, J., \& Gang, Q. (2008). Mobile commerce user acceptance study in China: A revised UTAUT model. Tsinghua Science and Technology, 13(3), 257-264. https://doi.org/10.1016/S1007-0214(08)70042-7

Roscoe, J.T. (1975). Fundamental research statistics for the behavioral sciences. 2nd edn. New York: Holt, Rinehart, and Winston.

Rainie, L., Brenner, J., \& Purcell, K. (2012). Photos and videos as social currency online. Pew Internet \& American Life Project, accessed October 22, 2019. http://www.pewinternet.org/2012/ 09/13/photos-and-videos-as-social-currency-online

Rattenbury, T., Good, N., \& Naaman, M. (2007). Towards automatic extraction of event and place semantics from flickr tags.Proceedings of the 30th Annual International ACM SIGIR Conference on Research and Development in Information Retrieval, 103-110.

Rzeszewski, M., \& Luczys, P. (2018). Care, indifference and anxiety- attitudes toward location data in everyday life. International Journal of GeoInformation, 7(10), 1-15. https://doi.org/10.20944/preprints201807.0214.v1

Schaper, L.K., \& Pervan, G.P. (2007). ICT and OTs: A model of information and communication technology acceptance and utilisation by occupational therapists. International Journal of Medical Informatics, 76 (1), 212-221. https://doi.org/10.1016/j.ijmedinf.2006.05.028

Taylor, A., Celuch, K., \& Goodwin, S. (2002). Technology readiness in the E-insurance industry: An exploratory investigation and development of an agent technology E-consumption model. Journal of Insurance Issues, 25(2), 142-165

Tosuntas, S.B., Karadag. E., \& Orhan, S. (2015). The factors affecting acceptance and use of interactive whiteboard within the scope of FATIH project: A structural equation model based on the Unified Theory of acceptance and use of technology. Computers \& Education, 81, 169-178. https://doi.org/10.1016/j.compedu.2014.10.009

Tussyadiah, I.P., \& Zach, F.J. (2012). The role of geo-based technology in place experiences. Annals of Tourism Research, 39(2), 780-800. https://doi.org/10.1016/j.annals.2011.10.003

Urumsah, D., Quaddus, M., \& Galbreath, J. (2011). An investigation into the factors influencing consumers to use e-services of Indonesian airlines: The role of motivation. In Proceedings of the 19th European Conference on Information Systems. Aalto University, Finland. http://hdl.handle.net/20.500.11937/48280

Venkatesh, V., Morris, M.G., Davis, G.B., \& Davis, F.D. (2003). User acceptance of information technology: Toward a unified view. MIS Quarterly, 27(3), 425-478. https://doi.org/10.2307/30036540

Venkatesh, V., Thong, J.Y., \& Xu, X. (2012). Consumer acceptance and use of information technology: extending the unified theory of acceptance and use of technology. MIS quarterly, 157-178. https://doi.org/10.2307/41410412

Welsh, K.E., France, D., Whalley, W.B., \& Park, J.R. (2012). Geotagging Photographs in Student Fieldwork. Journal of Geography in Higher Education, 36(3), 469-480. https://doi.org/10.1080/03098265.2011.647307

Young, A.L., \& Quan Haase, A. (2013). Privacy protection strategies on Facebook. Information, Communication \& Society,16(4),479-500. https://doi.org/10.1080/1369118X.2013.777757

Zeng, B., \& Gerritsen, R. (2014). What do we know about social media in tourism? A review, Tourism Management Perspectives, 10, 27-36. https://doi.org/10.1016/j.tmp.2014.01.001

Zheng, V.W., Zheng, Y., Xie, X., \& Yang, Q. (2010). Collaborative location and activity recommendations with GPS history data, in: Proceedings of the 19th International Conference on World Wide Web - WWW'10. Presented at the 19th international conference, ACM Press, Raleigh, North Carolina, USA, p. 1029. https://doi.org/10.1145/1772690.1772795

Zhou, T. (2017). Understanding location-based services users' privacy concern: An elaboration likelihood model perspective, Internet Research, 27(3), 506519. https://doi.org/10.1108/IntR-04-2016-0088

Zhou, T. (2013). An empirical examination of user adoption of location-based services, Electronic Commerce Research, 13(1), 25-39. https://doi.org/10.1007/s10660-013-9106-3

*** Pew Research Center (2019). Location-based services. accessed September 14, 2019. http://pewinternet.org/Reports/2013/Location.aspx

*** World Digital Report (2019). accessed on 07/05/2019. https://datareportal.com/reports

Article history: $\quad$ Received: $12.10 .2020 \quad$ Revised: $24.12 .2020 \quad$ Accepted: 11.01 .2021

